\title{
Research on the College Students' Competition Credit-Assisted Management System for Practical Universities
}

\author{
Yucheng Zhang, a, Lidong Song ${ }^{2, b}$ and Wenzhun Huang ${ }^{3, c}$ \\ ${ }^{1}$ Department of Electronic Information Engineering, Xijing University, Xi'an, China \\ ${ }^{2}$ School of Computer Science and Technology, Xi'an University of Science and Technology, Xi'an \\ China \\ ${ }^{3}$ Department of Electronic Information Engineering, Xijing University, Xi'an, China \\ a58911533@qq.com, b1194216819@qq.com, ${ }^{\mathrm{a}} 1051917312 @ q q . c o m$
}

Keywords: College Student; Competition; Credit-Assisted; Management; Practical Feature.

\begin{abstract}
In this paper, we conduct the research on the college students' competition credit-assisted management system for practical universities. Due to talents training goal of colleges and universities there is a progressive transformation relation, therefore, in the process of the talents training target decomposition, should not only pay attention to the logic of vertical target, and to pay attention to the correlation level goal, coordination, emphasize the overall effect and reasonable decomposition of the target. The talents training goal of colleges and universities management mode is the key to how to the school's overall training goal and professional training objectives into faculty and student's personal goals, and to mobilize staff and students actively to achieve personal goals, so that the organizational goals to complete. In the process of target decomposition to emphasize the participation of faculty and students, pay attention to target at the level of decomposition and conversion.
\end{abstract}

\section{Introduction}

The cultivation of applied talents problem has also has caused the great attention of many universities, as many colleges and universities have launched a new round of talent training mode reform the study of applied talents training mode results emerge in endlessly. These research results to promote the reform of the personnel training mode, leading all accurate orientation, characteristic development, colleges and universities to re-examine their own talent training objective and specification, we will accelerate reform of the teaching, to further promote the development of higher education, cultivate more talents for social and economic development of applied talents has very important significance.

Applied undergraduate education belongs to higher levels of higher education. It is to train applied and technical personnel as the goal. Applied undergraduate education is different from general in the traditional sense of the undergraduate education and it has the following main features. Look from the personnel training specification, it cultivate the high-quality talents in the field of applied technology, rather than the ordinary undergraduate cultivating academic and research talents. Look from theory teaching system, although the theory of the applied undergraduate curriculum system emphasizes the applicability, but should reach a certain theory in the depth and breadth, enable students to master the professional capacity have sufficient theoretical support, and the teaching of higher vocational college theory with the "good enough" for the primary principle [1-3].

Rising the undergraduate course colleges and universities of general applied talents training new characteristic mainly reflects in the following respects. (1) Applied professional characteristics of the professional structure which emphasizes strong professional application, and are reasonably generous discipline foundation as both highlight the applied professional as a solid platform of the industry background also has wide scope of general disciplines background is certain professional or embodies application characteristic of main subject as a strong support. (2) On the practical characteristics of the 
talent cultivation is generally not pursue the academic university "profound knowledge", but also different from the higher vocational college. This kind of talents should have moderate solid theory foundation, wide professional to adapt to the surface, especially pay attention to the innovation ability to put theoretical knowledge into practice. (3) Type teaching characteristics in teaching as the center, make "teaching" or individual for "teaching-research colleges and universities. Teaching mode should be from the theory of leading to theory and ability and heavy this kind of colleges and universities are conducting scientific research, but research project mainly take place developmental research.

In people-oriented modern school management must be set up based on the staff thought, establish an effective incentive mechanism, fully mobilize the enthusiasm of faculty teaching, so as to realize the management goal, improve the management level, promote the teaching efficiency, effectively implement the party's education policy. There are many factors that can affect the enthusiasm of the people, among them, the unfair factors is very important. For illustration, in the following Fig. 1, we show the general impression of the modern universities [4-5].

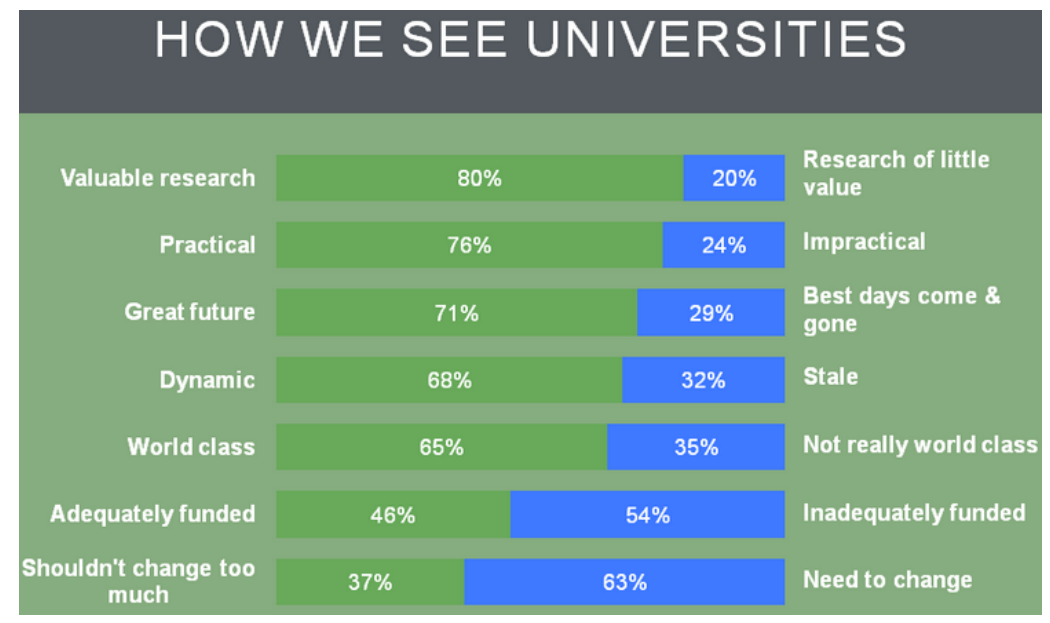

Figure 1. The General Impression of the Modern Universities

In this paper, we conduct research on the college students' competition credit-assisted management system for practical universities. The current development of basic higher education is in the big and huge adjustment period that drives the demand for high quality education strongly teaching reform in colleges and universities. But the construction of teaching management system lags behind the reform of education management, some of the original system can't meet the needs of the practical teaching management. So we must according to the new training plan that be revised in time and make the management system to keep up with the modern development of teaching management to realize the management standardized, scientific and institutionalized.

\section{The Proposed Methodology and Perspective}

The Undergraduate Teaching Reform. With the high development of science and technology and economy material prosperity and rapid social change, which requires the school to give the students should be for his life are the most valuable thing, that is to improve the overall quality and the strain capacity. Years of education practice show that the graduate students of institutions of higher learning can smoothly enter the social various post-employment with the school teaching quality and students' quality has a lot to do. The reform of the current teaching method is not stay where some or on which a method of keeping improving, but more and more tend to a variety of the methods the flexible combination of a variety of the means, tend to the improvement of the comprehensive method and application, tend to explore the matching different ways under different situations. In a course of the whole teaching activity, teachers can according to the primary teaching contents reasonably use the 
multimedia demonstration function and the traditional teaching method, experimental method, the explanation, the computer demonstration of the teachers and students combined operation is flexible, play their respective advantages, in order to obtain the best teaching effect. For the different courses, teachers can also according to the nature of the curriculum and teaching contents need to be flexible choice of teaching methods such as mathematical curriculum focuses on argument is derived [6].

Teaching method of the implementation of the work process oriented, that should with national conditions of our country, combining with the reality of our country, explore the working process of the curriculum system with Chinese characteristics, in the particular as described below. (1) Schools should improve various management systems. For the implementation of the work process oriented teaching method provides effective external security. Educational administration department should also reform the traditional teaching management pattern, to develop new curriculum implementation, evaluation, evaluation mechanisms, take effective measures to safeguard based on working process oriented curriculum system development and the smooth implementation. (2) Government regulation should be made administrative areas, encourage enterprises to participate in school teaching, from the tax, for example, the law regulation policy. Schools should also actively explore the "work-integrated learning" mode and enterprises to carry out all-round various forms of the cooperation. (3) Strengthen the teacher's practice ability can also encourage teachers and enterprise cooperation, conduct related research work, which can help the enterprise to solve the problems encountered in actual production, and can make the teacher perceptual knowledge obtained in the process of project research project.

The Practical Universities. Education concept to basic age characteristics, and to change with the progress of the era constantly adjust, as also is to change our education ideas, constantly update our concepts of education. From the point of the nature of basic education, education includes not only imparting knowledge, skills, training, should also include person's ideological and moral cultivation, the psychological adjustment and physical exercise. As applied undergraduate colleges, inheritance centered education thoughts, update with teachers as the main body of education concept is to develop strong engineering practice ability and innovative spirit of the premise of the applied undergraduate talents. The following Fig. 2 demonstrates the principles.

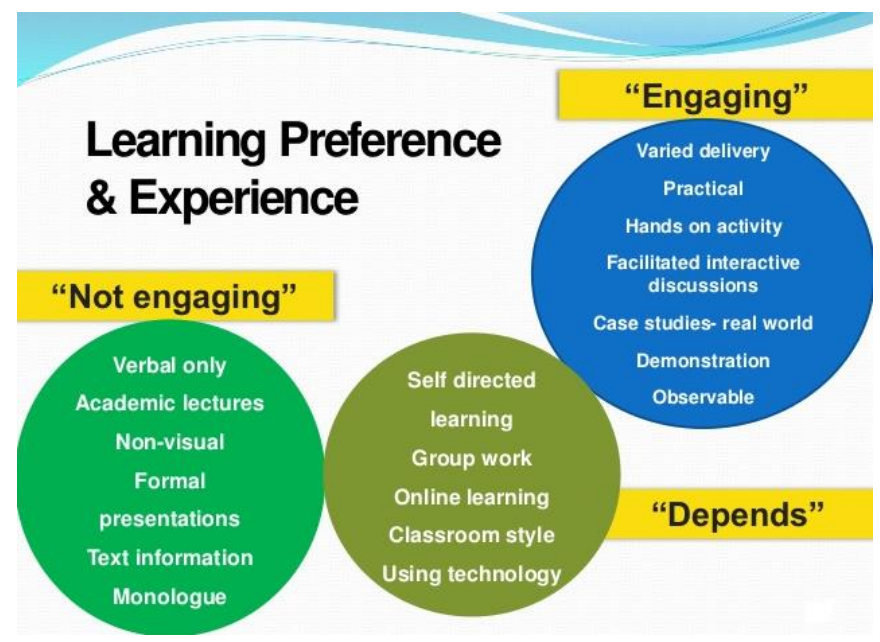

Figure 2. The General Features of the Practical Universities

At present, the diversified school-running orientation on the status of institutions of higher learning mainly reflects how handle the relationship between the school type and talents training target. Talent training is the earliest form of the colleges and universities, as well as the most important and most fundamental functions. Since the newly built undergraduate course colleges and universities mainly cultivate application-oriented talents for local services, school types determine for the modern applied undergraduate colleges is logical. For a long time due to our country's higher education has been in the 
phase of the elite, so at the beginning of the stepped into the stage of the public, these problems are understandable. But we should see more, the undergraduate course education to cultivate the applied talents is not only beneficial to meet the needs of social unit of choose and employ persons of talent; But also to meet the students' demand for higher education, not only can satisfy the social demand for higher education, but also the needs of the development of higher education itself [7].

Teacher professional development is refers to the teacher in the whole professional career, through a series of training, the acquisition of education professional knowledge skills, implementation of the professional autonomy and professional moral. (1) Professional spirit. This is the power of teachers' professional development as it can be shown in love students, rigorous scholarship, unity cooperation, selfless dedication, responsibility, the primary participation. (2) Professional knowledge. Professional knowledge is the basis of specialization of teachers, mainly by the ontology knowledge, conditional knowledge and practical knowledge. In general, university teachers are value for ontology knowledge, much of the conditional knowledge and practical knowledge accumulation. (3) Professional ability. Professional ability is the guarantee of the teacher's professional development, it mainly includes: the education teaching ability, scientific research ability, guide students life-long learning ability, etc.

The School Credit-Assisted Management System. Setting of the organization of management of colleges and universities is the concentrated and primary reflection of university management level and management benefit is the comprehensive improve the quality of scientific research, teaching, development of modern higher education, the education of talents with innovative spirit and practice. Institutions of higher learning to reduce redundancy and improve the teaching efficiency is necessarily to the breakthrough of the reform of the institutions, nowadays, the reform of the institutions of higher learning institutions has become a top priority in the development of colleges and universities.

In format $i$ on management using the modern information technology and scientific management methods to replace manual operation and the traditional management mode, implementation process of restructuring, achieve high efficiency, high level of modern management. In particular, the use of information technology in information sharing on the basis of the automation for title department of information management in colleges and universities, to achieve convenient communication between departments between superior and subordinate to realize the data sharing between different functional departments and coordination. All kinds of the management information system based on campus network can not only meet daily administrative office, financial management, personnel management and student management and can effectively improve the management efficiency of the school [8].

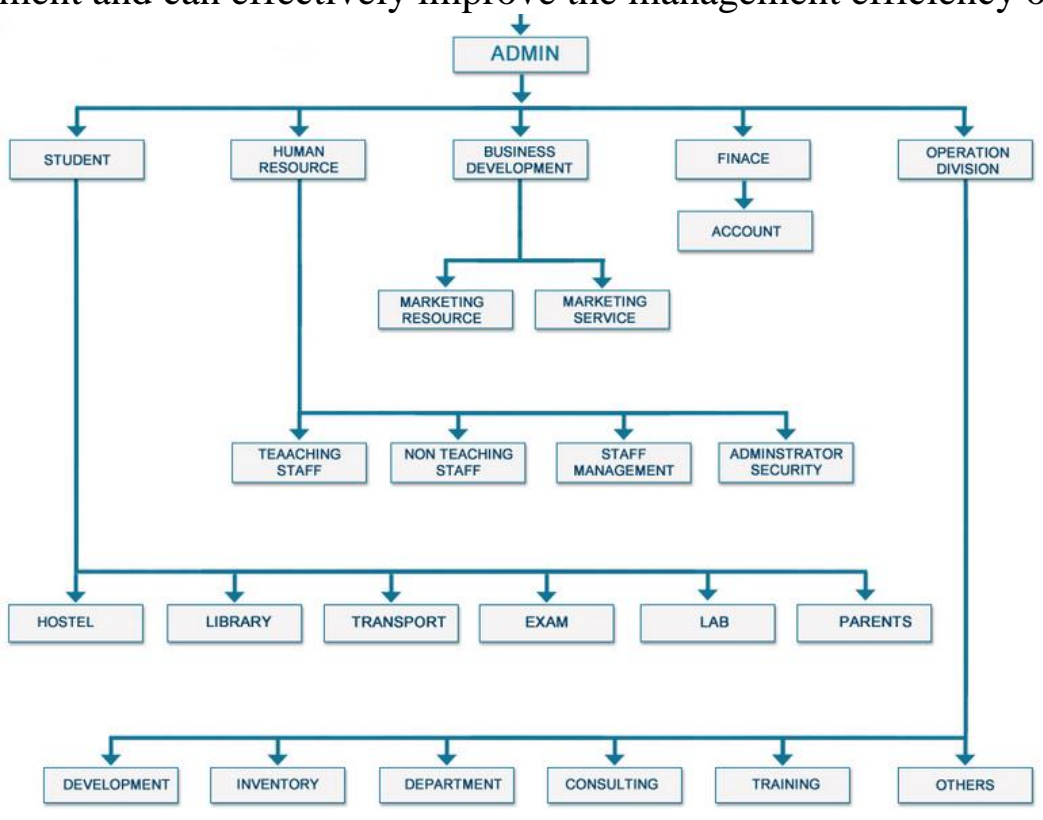

Figure 3. the General Procedures of the School Management System 
The innovation of the era of knowledge economy is highly developed in computer and information communication network conditions, as far as possible in the global knowledge sharing on the basis of innovation. Need knowledge management and the knowledge innovation. Visible to a certain extent, knowledge management is the foundation of the knowledge economy. The meaning of knowledge management includes two aspects, on the one hand, refers to the management of information, through the intelligent information processing and information knowledge value-added, find, organize, share, and the use. Therefore, we propose the corresponding suggestions as the follows. (1) Responsibility consciousness. Responsibility is a kind of personal character accomplishment, ideology, mental state, is a reliable way to success, enhance responsibility consciousness is the primary focus of maximum benefits of fine management in colleges and universities. Colleges and universities in the process of implementing fine management, according to post responsibility clear, strengthening management, the principle of quantitative evaluation. (2) Humanistic ideas. Concept of the fine management to colleges and universities must come first, hold fast to "person" this center, put the person's work in the first place, as fully understand people, respect people, in the management of each link is full of the humanistic care, to mobilize their initiative, enthusiasm and creativity to organize all the management activities. (3) Service attitude. In the process of the fine management of colleges and universities, we should establish the idea of "whole-hearted service, sincere service", students, parents satisfaction as a measure of the school management performance and personnel at various levels and of the key indicators of general performance, students, parents, social satisfaction evaluation mechanism as the supervision and guarantee, pay more attention to meet the demand of the server, with careful attitude, fine process and create the high-quality goods.

The College Students' Competition. Different types, different levels of course contests are racing to develop the competition not only helps to cultivate the students' self-confidence and a sense of the achievement, inspire students' autonomous learning and the enthusiasm of initiative study, at the same time, also helps to cultivate the students' practical ability and the team cooperation spirit, promote the discipline teaching reform and improve teaching quality.

Today, quality education has been gradually carried out, and the competition of the science and technology not only can effectively stimulate the creation of the college students' enthusiasm, exercise the ability to create that can also train their innovative consciousness. Therefore, organizing college students to participate in the competition is to train innovative talents of science and technology of all types and at all levels in the form of a kind of extremely effective. Subject contest organization is a systematic project, need school educational administration departments, the participating students, teachers, discipline in colleges and students in college aspects of coordination, and work together. In this process, the use of scientific management methods, forming a good incentive mechanism is very important. In participating in the process of the selection and training of students, teachers play an important role, a high level of competition depends on the participation of various branches teacher, teachers is the guarantee training effect and leader of the outstanding achievements.

- Local colleges and universities must be innovative talents training target oriented, will work discipline competition and the basic organic combination of the current teaching reform, make subject competitions become important contents in the teaching link. Discipline competition achievements and problems of the work can provide reference for the teaching reform. Results of local university disciplines race can be reflected students' mastery of basic professional knowledge and practical ability, and further indicates the weak link in students in classroom teaching, etc., these problems should be brought into the teaching reform of thinking that can make more targeted teaching reform.

- Perfect discipline competition management mechanism that should first clear management institutions and the agencies of competition of responsibilities, to ensure that communication between the departments strong, run smoothly and provide powerful support for development of the discipline competition in college and universities. 
- As a powerful intellectual support of student discipline competition work, guidance of teacher role cannot be ignored. Therefore, local colleges and universities in the process of work in promoting the discipline competition must attach great importance to guide the construction and development of teachers. In the process, not only to invite academic experience, respected teachers, head of the race, more should pay attention to guiding teachers age, titles such as the gradient structure.

\section{Conclusion}

In this paper, we conduct research on the college students' competition credit-assisted management system for practical universities. Practice has proved that the correlation of a sense of accomplishment and satisfaction is the largest, without a sense of the accomplishment of the college teachers, work enthusiasm is not high. Study found that whatever professional, professional titles of the university teachers, challenging work, a sense of accomplishment and the specialty are higher than primary and secondary school teachers, learn with specialty of college teachers tend to pick one side alone, in the academic responsibility system of colleges and universities. How to respect their create value, to give them to create a loose free academic environment and humane environment of development, is an important subject of colleges and universities manager. Therefore, under this background, we propose the competition credit-assisted management system to enhance contemporary college management architecture. In the recent future, we will conduct more in-depth analysis on the related issues to form the better combination of the educational techniques.

\section{Acknowledgements}

Research on General issues of teaching reform of Xijing University in 2015, Project name: Research and Practice on the IT Outstanding Engineers Education Training Plan based on University-Enterprise Cooperation Alliance, project number:JGYB1527.

This paper was financially supported by Research on real time monitoring system of surface subsidence based on GPS and GPRS, Scientific research fund of Xijing University in 2013, project number: XJ130102.

\section{References}

[1] Samuelsson, Katarina, and Sverker Lindblad. "School management, cultures of teaching and student outcomes: Comparing the cases of Finland and Sweden." Teaching and Teacher Education 49 (2015): 168-177.

[2] Soh, Kaycheng. "Finland and Singapore in PISA 2009: similarities and differences in achievements and school management." Compare: A Journal of Comparative and International Education 44.3 (2014): 455-471.

[3] Yamada, Shoko. "Determinants of 'community participation': the tradition of local initiatives and the institutionalization of school management committees in Oromia Region, Ethiopia." Compare: A Journal of Comparative and International Education 44.2 (2014): 162-185.

[4] Grossman, Thomas A., Vijay Mehrotra, and Mouwafac Sidaoui. "A Student-Centered Approach to the Business School Management Science Course." INFORMS Transactions on Education 16.2 (2016): 42-53.

[5] Khattri, Nidhi, Cristina Ling, and Shreyasi Jha. "The effects of school-based management in the Philippines: an initial assessment using administrative data." Journal of development Effectiveness 4.2 (2012): 277-295. 
[6] Berry, Diane C., et al. "Recruitment and Retention Strategies for a Community - Based Weight Management Study for Multi - Ethnic Elementary School Children and Their Parents." Public Health Nursing 30.1 (2013): 80-86.

[7] Lehmann, Johannes, and Stephen Joseph, eds. Biochar for environmental management: science, technology and implementation. Routledge, 2015.

[8] Van Roe yen, Linda Sue. "Management of pediatric asthma at home and in school." Nursing Clinics of North America 48.1 (2013): 165-175. 